\title{
O DESIGN APLICADO À SAÚDE MENTAL - A EXPERIÊNCIA DO LABORATÓRIO DE DESIGN SOLIDÁRIO COM A ASSOCIAÇÃO ARTE E CONVÍVIO
}

\author{
Karina Salgueiro De Luca \\ Universidade Estadual Paulista "Júlio de Mesquita Filho" - UNESP \\ karinasdeluca@gmail.com \\ Karina Freire Gomes \\ Universidade Estadual Paulista "Júlio de Mesquita Filho" - UNESP \\ Karina.freire314@gmail.com \\ Claudio Roberto y Goya \\ Universidade Estadual Paulista "Júlio de Mesquita Filho" - UNESP \\ goyaclaudio@hotmail.com
}

Resumo: $O$ trabalho a seguir trata-se da parceria entre a Associação Arte e Convívio de Botucatu e o Laboratório de Design Solidário - Labsol, da UNESP de Bauru. Esta parceria consistiu na criação e elaboração de embalagens para jogos pedagógicos e uma nova linha de encadernação, assim como um espaço destinado à uma lanchonete para o Arte e Convívio Café. Conceitos como sustentabilidade, ecodesign e economia solidária basearam a realização dos projetos e proporcionaram a concepção de produtos artesanais específicos que delimitaram o espaço do Café, tornando-o aconchegante e adquirindo uma característica própria desejada pela Associação. Foi trabalhado também uma identidade visual para o ambiente e com isso um novo logo para melhor representar a identificação do estabelecimento assim como aplicações deste nas vestimentas e cardápios fabricados pela própria Associação.

Palavras-chave: processo de criação, produtos artesanais, projeto.

Abstract: The following work is about the partnership formed between the Art \& Coexistence Association of Botucatu and the Solidary Design Laboratory - Labsol of UNESP Bauru. This partnership consisted in the creation and development of packaging for educational games and a new line of hand-bound notebooks, as well as a space destined for a snack bar for Art \& Coexistence Café. Concepts such as sustainability, ecodesign and solidary economy based the implementation of the projects and provided the conception of specific hand-crafted products that delimit the space of the Café, making it cozy and acquiring a characteristic desired by the 
Association. A visual identity for the environment was also worked and with it a new logo to better represent the identification of the establishment as well as its applications on the menu and garments, which were produced by the Association.

Keywords: creative process, hand-crafted products, project.

\section{INTRODUÇÃO}

O Projeto de Extensão Labsol - Laboratório de Design Solidário, pertencente ao Departamento de Design da Faculdade de Arquitetura, Artes e Comunicação (FAAC), da Universidade Estadual Júlio de Mesquita Filho - UNESP - Campus de Bauru, possui como principal proposta o desenvolvimento de ações conjuntas entre o design e o artesanato como patrimônio cultural. O Labsol trabalha partindo de um tripé constituído pelos conceitos de Sustentabilidade, Ecodesign e Economia Solidária e atende grupos e comunidades de artesãos orientando e qualificando seus produtos. Promove, em parceria com grupos artesãos, projetos e ações que agregam valor aos produtos e melhorem os processos produtivos, levando em conta a cultura e a comunidade local. (GOYA, et al. 2014)

A Associação Arte e Convivio, fundada em 1995 e localizada em Botucatu - SP, é administrada por um grupo de profissionais de serviços de saúde mental, usuários, familiares e líderes comunitários municipais, que buscam a inclusão de pessoas que possuem sofrimentos psíquicos no merado de trabalho, melhorando a convivência, a assistência e o respeito através de diversas oficinas inclusivas para geração de renda, como encadernação, costura, bordado, mosaico, entre outras. Assim, demonstram sua própria capacidade e uma nova perspectiva, aumentando sua qualidade de vida e confiança para conquista de sua reabilitação psicossocial.

O contato entre o Labsol e a Associação ocorreu por via da Design Possível, projeto sem fins lucrativos que aplica o design como ferramenta de transformação social, desenvolvendo ações e atividades educacionais que buscam a sustentabilidade e estimulem o empreendedorismo. Após a realização de seis encontros mediados pela Design Possível, foi assumido um vínculo com o Labsol, propondo novos projetos e auxílio em conjunto.

\section{DESENVOLVIMENTO}

O projeto participou das reuniões finais da parceria com a Design Possível, com o objetivo de conhecer a problemática, e pôde reconhecer muito potencial e a oportunidade de ajustes. Foram sugeridas intervenções, que foram bem recebidas pelos técnicos da associação e dirigentes e a partir de então, alguns trabalhos foram realizados.

O primeiro passo, parte da estratégia escolhida para acolher as demandas da associação, foi a participação nas reuniões nos grupos de trabalho a que fomos convidados. A associação é bastante versátil, e conta com oficinas, que são 
autossuficientes do ponto da vista da gestão da sua produção e criação de seus produtos. Neste artigo serão mencionadas as oficinas de encadernação, mosaico e costura.

\subsection{Oficinas da Associação}

Logo ao nos depararmos com os objetos produzidos pelas oficinas da Associação, notamos a utilização de figuras impressas em cadernos, almofadas e outros, que foram retiradas da Internet. Explicamos que tal prática pode não trazer consequências agradáveis, pois as imagens, embora na maioria das vezes apareçam de forma anônima, são fruto do trabalho de outras pessoas, que podem em algum momento requerer direitos autorais, o que, minimamente, pode repercutir de modo negativo na imagem propagada pela associação perante seu público alvo.

Outro aspecto importante, bastante frisado no projeto Labsol e baseado no capítulo "Identidade e diversidade" do livro Design + Artesanato - O caminho brasileiro (BORGES, 2011), é que a produção artística e artesanal prescinde de alguns pressupostos, como ser capaz de expressar a identidade a que se insere os artesãos/artistas. Trata-se de uma forma de legitimar o trabalho como parte integrante da cultura local, e não apenas uma reprodução de técnicas alheias, sem qualquer reflexão. Isso diferencia o artesanato brasileiro, recheado de riquezas e potencialidades, da produção meramente assistencialista, que visa angariar recursos para uma parcela da população "digna da piedade" alheia, a quem se deve, por uma questão humanitária, prestar auxílio.

Esse não é caso em absoluto da Associação Arte e Convívio, que possui uma longa trajetória na conquista de sua identidade, como vimos nos objetos produzidos pelas oficinas da Associação.

A oficina de encadernação possui uma grande variedade de produtos, entre eles blocos, agendas, cadernetas, cadernos de desenho, além de um número extenso de criação de estampas, sempre a partir de tecidos. A iniciativa para esta oficina foi a proposta de incrementar a linha de cadernos oferecidos, com materiais como tecidos estampados artesanalmente em serigrafia com motivos desenvolvidos exclusivamente para a Associação e tecidos chita com diversas cores e estampas. Foram criadas novas linhas de produção: a linha Glam, que conta com capas de tecido metalizado e com estampas mais sóbrias, a Xiquita, que tem a característica de cores vivas e típicas do Brasil, como vemos nos capas de chita, e a Raízes, que conta estampas que remetem à flores e outros elementos da natureza brasileira. O resultado final foi traduzido em belos cadernos, conforme a figura.

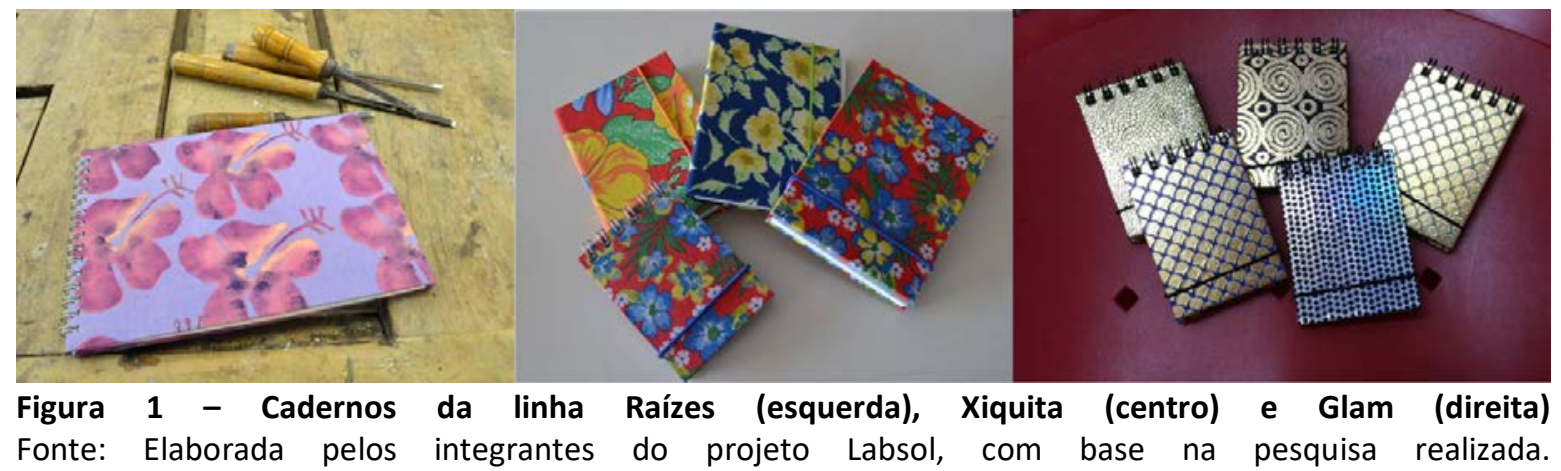


A oficina de mosaico produz vasos, mesas, placas de identificação de número de casa, bancos e outros móveis, quadros etc. Notamos que o acabamento é bastante cuidadoso, porém a técnica de mosaico necessita de aprimoramento para criar figuras mais complexas. Foram propostas algumas mudanças na produção, de modo a tornar as composições dos mosaicos mais interessantes e trazer mais valor aos produtos finais. Uma delas foi a utilização de materiais reciclados, como azulejos, cerâmicas e madeira. 0 mosaico seria então realizado sobre estes materiais reaproveitados. Estas novas técnicas resultaram em peças mais sustentáveis, baseadas no tripé do Labsol.

A oficina de costura fabrica almofadas, vestimentas em geral, tiaras e tapetes, dentre outros. Utiliza as técnicas de bordados, patchwork e trabalhos em crochê, realizando as atividades com materiais diversos, como jeans, feltro, tecidos de algodão, entre outros. A oficina de costura é responsável pelos jogos pedagógicos: produto exclusivo e de grande aceitação no mercado. O Jogo Pedagógico consiste de peças confeccionadas artesanalmente, utilizando principalmente de feltro de cores diversas. Foi proposta a melhoria da embalagem do jogo, que era confeccionada de tecido e sem uma identificação do que continha. A sugestão dada pelo Labsol foi uma embalagem em plástico, bordada com tecido na sua abertura, que permitia a visualização do jogo, sem comprometer a identidade da oficina de costura e do produto que a embalagem continha.

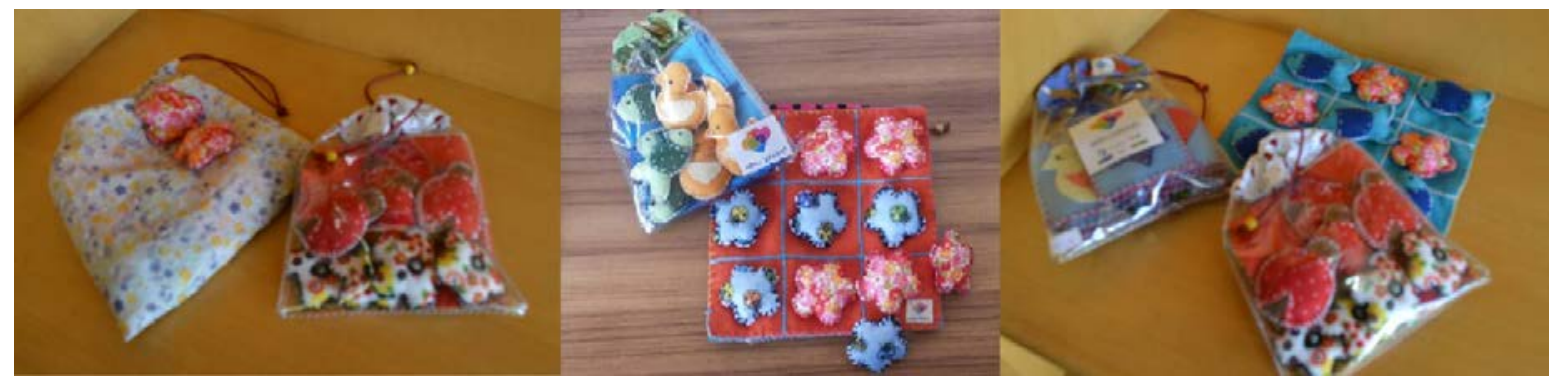

Figura 2 - Embalagens dos jogos pedagógicos antes (primeira imagem) e depois (segunda e terceira imagens)

Fonte: Elaborada pelos integrantes do projeto Labsol, com base na pesquisa realizada.

Durante o processo com a Arte e Convívio, verificou-se que a loja, onde os produtos eram expostos não atendia as expectativas dos próprios dirigentes. O Labsol mais uma vez entrou em cena pra compreender a demanda, propondo uma reforma do espaço de exposição, de modo que não demandasse alto custo e transtornos. A sala usada para loja foi reposicionada, móveis reformados e remodelados e a vitrine foi refeita. 0 resultado ficou bastante interessante, especialmente quando compara-se o antes e depois da mudança.

\subsection{Arte e Convívio Café}

O maior projeto realizado na parceria com a Arte e Convívio consistiu na criação e elaboração de um espaço destinado à uma lanchonete, no saguão de um ainda remanescente hospital psiquiátrico do município de Botucatu, o Hospital Psiquiátrico Municipal Professor Cantídio Moura Campos.

O objetivo principal foi deixar o espaço alegre, aconchegante e criativo, e que 
passasse a identidade da Associação, para contrastar com o local do Café que, por ser um hospital, muitas vezes é visto como um lugar de sofrimento e monótono. Para isso, foram utilizados objetos desenvolvidos pela própria Associação, o que ajudaria não só na composição do ambiente, mas também na divulgação do trabalho das oficinas e agregaria valores atrativos ao mercado. Os objetos desenvolvidos deveriam também atender ao tripé visado pelo Labsol: sustentabilidade, ecodesign e economia solidária - valorizando o trabalho do ser humano e adquirindo renda de forma cooperativista, como explicado em Introdução à Economia Solidária (SINGER, 2002).

Para isso, foi necessário observar e analisar o espaço destinado ao Café, sendo realizadas medições do local para facilitar a discussão e planejamento do ambiente. Como foi mencionado anteriormente, a Associação ficou responsável pela personalização do local, aplicando tecidos e rejunte colorido nos azulejos da parede, dando mais vida e cor ao ambiente. Coube à eles também providenciarem os móveis a serem utilizados no Café, como mesas, bancos e almofadas.

Após realizarmos as medições, partimos para a criação e concepção do Café, seguindo a metodologia de projeto de produto descrita no livro, Projeto de Produto (BAXTER, 2011). Ao Labsol coube a responsabilidade da delimitação da área de alimentação e convivência, que foi feita com quatro caixotes compostos de madeira de reflorestamento, que foram montados no Laboratório de Materiais Didáticos e Processos - LMDP - da UNESP. Para elaborar os caixotes, foram desmontados e lixados pallets, tendo em mente o melhor aproveitamento da madeira. Durante a montagem final do ambiente, foi observado que além de delimitar o espaço do Café, os caixotes seriviriam também de mesas.

Com as sobras da madeira utilizada para a montagem dos caixotes, criamos molduras para pinturas abstratas de autoria dos integrantes do grupo Arte e Convívio, que serviriam de decoração para as paredes do ambiente do Café. As molduras deram mais requinte e valorizaram as criações dos integrantes. Esses elementos pessoais também ajudaram a decorar e compor o ambiente aconchegante e criativo que queríamos para o Café.

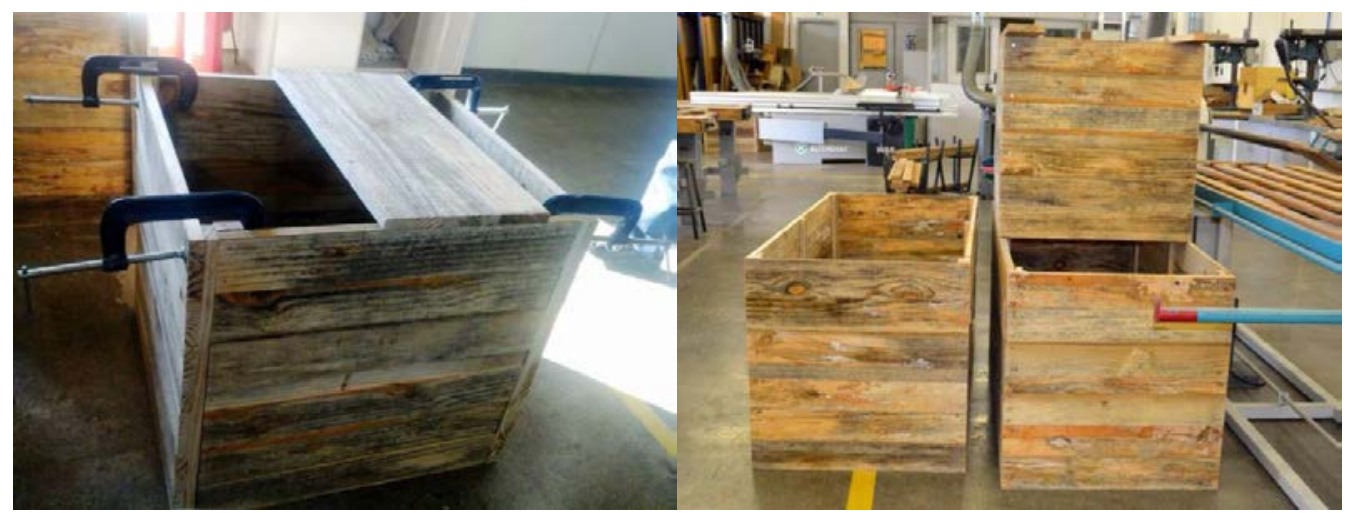

Figura 3: Montagem dos caixotes no Laboratório de Materiais Didáticos e Processos da UNESP

Fonte: Elaboradas pelos integrantes do Labsol, com base na pesquisa realizada.

Para a iluminação do ambiente, foram concebidas luminárias feitas a partir de 
materiais adaptados, como pratos de plástico e porta-canudos de lanchonete, que trouxeram um toque de inovação e ajudaram na composição de cores do ambiente. Na cozinha, foi aplicado um papel de parede de modo a que ficasse visível da praça de alimentação.

Para completar o projeto, implantamos um toldo na frente da janela de atendimento do bar, o que conferiu um tom bastante pitoresco e aconchegante à identidade visual do novo espaço. Essa foi outra forma encontrada pela associação arte e convívio para gerar cidadania por meio do trabalho aos seus usuários, retirando-se o estigma de incapazes e improdutivos, que recebem da sociedade como é constituída. A finalização do bar foi brindada com uma inauguração, a fim de mostrar aos demais parceiros mais uma iniciativa de sucesso.

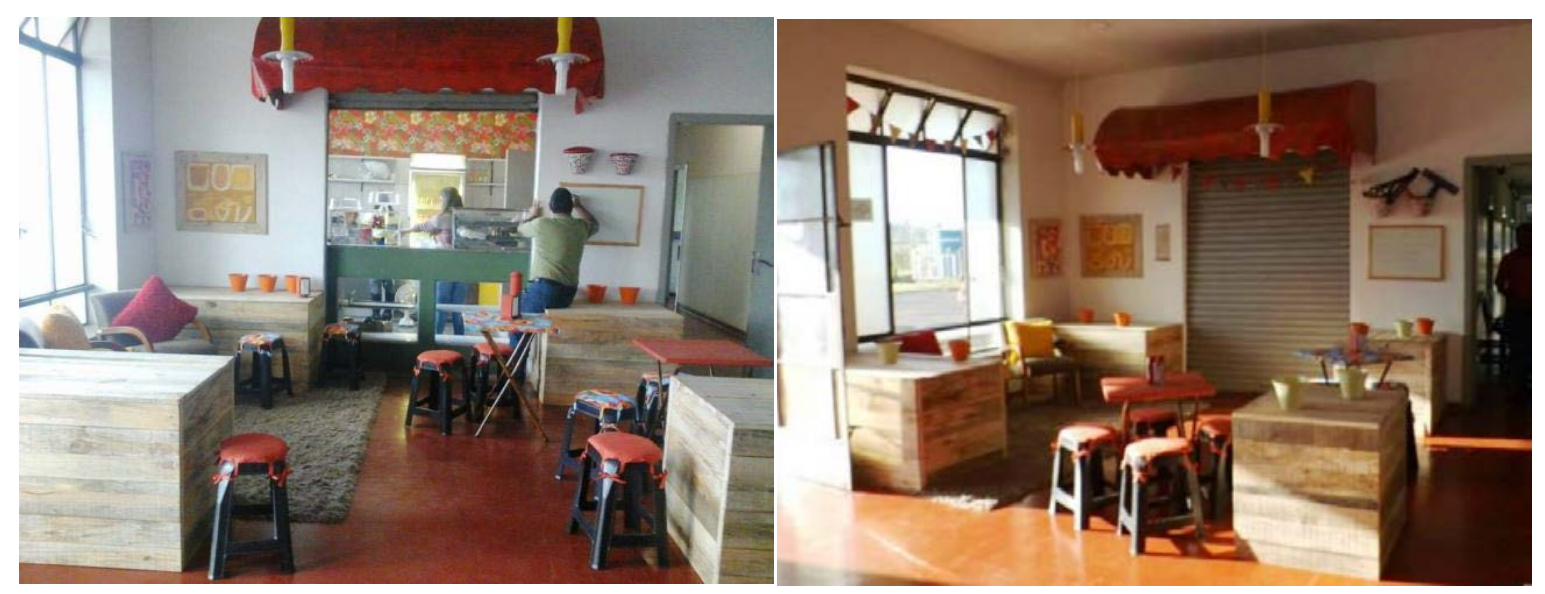

Figura 4: Espaço finalizado do Arte e Convívio Café

Fonte: Elaborada pelos integrantes do projeto Labsol, com base na pesquisa realizada.

\subsection{1: Identidade Visual do Arte e Convívio Café}

Após a elaboração do Arte e Convívio Café, viu-se a necessidade da criação de uma identidade visual específica para valorizar ainda mais o local e o trabalho dos integrantes. Foi definido que criaríamos um novo logotipo, que ainda remetesse ao logotipo da Associação, mas que tivesse suas próprias particularidades, sendo trabalhadas as cores, tipografias, traços, entre outros componetes. Com isso, utilizamos uma parte do logotipo atual da Associação. Deste modo o Café ganha sua própria identidade sem deixar de seguir a identidade da Associação como um todo.

O logotipo final que foi desenvolvido não tem uma cor fixa, podendo ser adaptado de acordo com suas diferentes aplicações. Foram feitos testes para a escolha da tipografia adicional ao logo. 


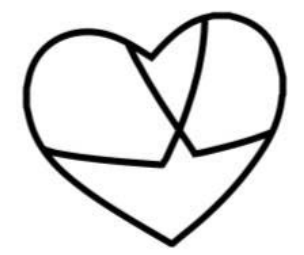

\section{ARIE E CONVÍVD}

Figura 5: Logotipo criado para o Arte e Convívio Café

Fonte: Elaborados pela integrante do Projeto Labsol, Tatiane Amano, com base na pesquisa realizada.

Para o cardápio, foram selecionadas algumas cores do logo principal e adicionadas ao marrom e creme, para referir-se melhor ao tema da identidade. Após a escolha das cores, foi consolidada a escolha do layout. Após a finalização da etapa gráfica, esta foi colada em pastas decoradas com chitas diversas produzidas pela Arte e Convívio.

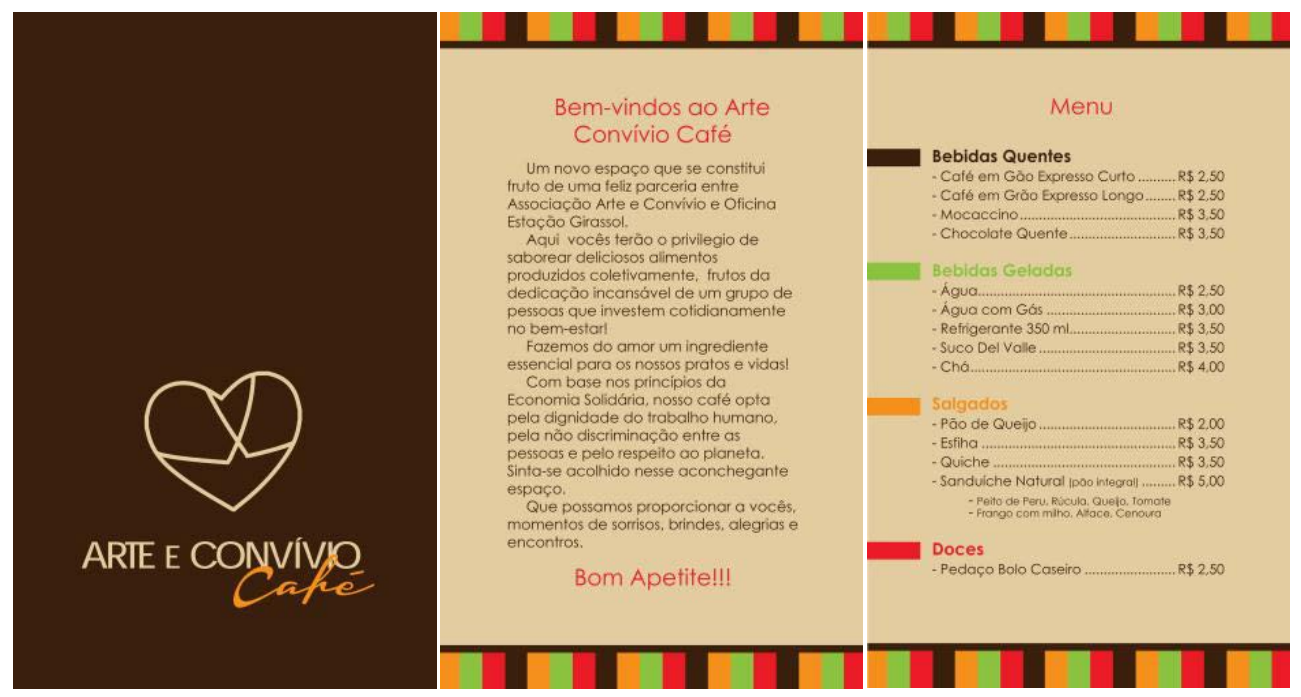

Figura 6: Layouts gráficos do cardápio: capa (esquerda), apresetação (centro) e menu (direita). Fonte: Elaborados pela integrante do Projeto Labsol, Tatiane Amano, com base na pesquisa realizada.

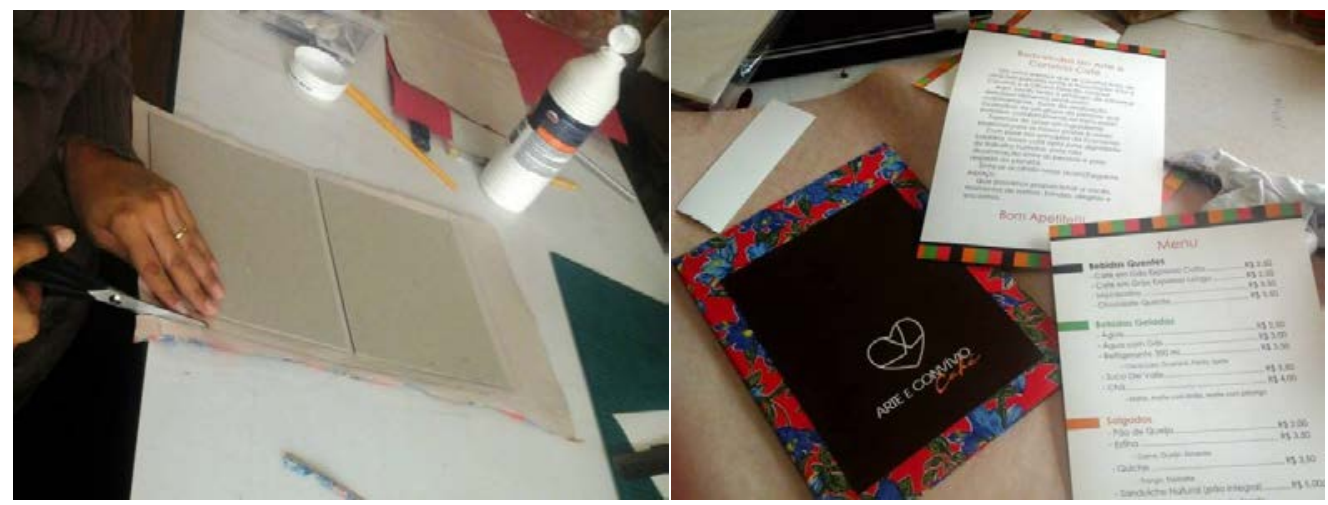

Figura 7: Montagem dos cardápios (esquerda) e produto final (direita).

Fonte: Elaborada por integrantes do projeto Labsol, com base na pesquisa realizada. 
Os logotipos também foram bordados em aventais produzidos pela própria Associação utilizando uma máquina de bordar doada à Arte e Convívio que se encontrava em desuso há muito tempo, devido à falta de conhecimento em seu manuseio. A máquina passou por revisões, permitindo assim realizar diversos trabalhos em conjunto com as oficinas de costura e bordados.

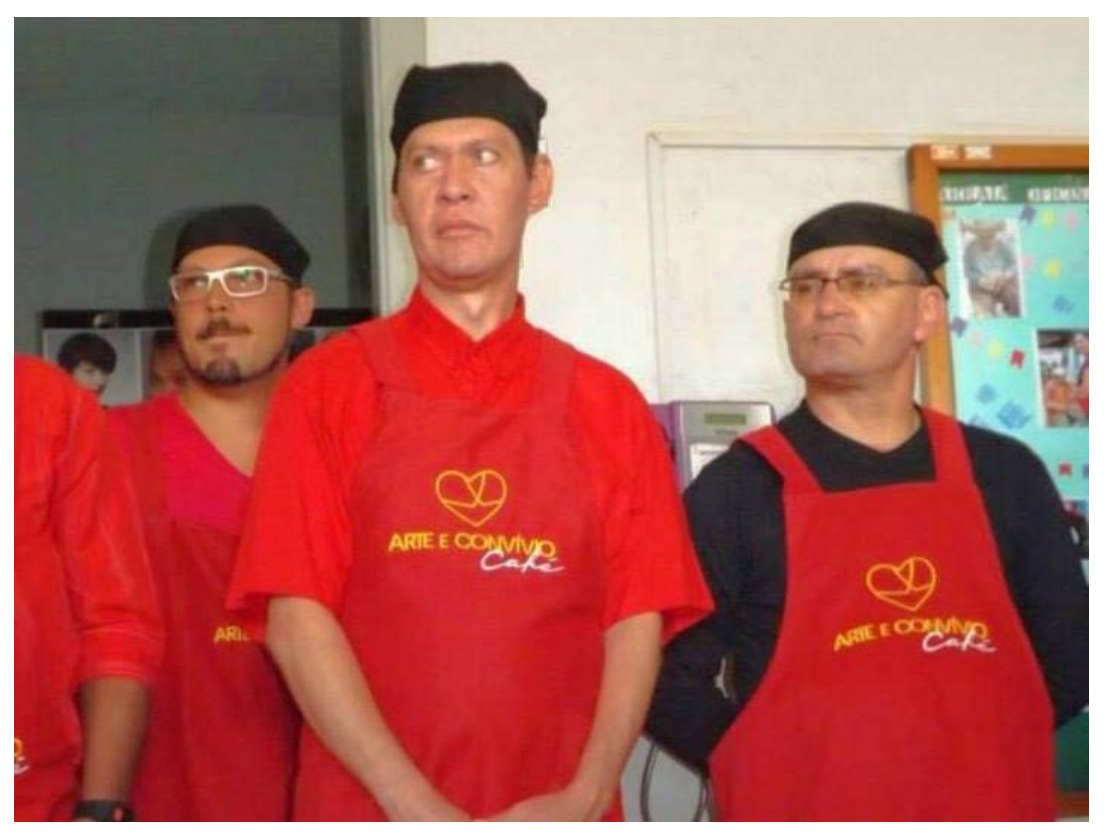

Figura 8: Aventais personalizados com o novo logotipo.

Fonte: Elaborada por integrantes do projeto Labsol, com base na pesquisa realizada.

\section{CONCLUSÃO}

A Associação Arte e Convívio acolheu o Projeto de Extensão Labsol extremamente bem, permitindo a realização conjunta de um projeto que conseguiu atingir as demandas propostas, exaltando os princípios visados pela equipe acadêmica: atender as comunidades transmitindo conhecimentos adquiridos no meio universitário, o que permite uma troca de conhecimentos e experiências muito rica.

\section{REFERÊNCIAS}

BAXTER, Mike. Projeto de produto - Guia prático para o design de novos produtos. 3 ed. São Paulo: Blucher, 2011.

BORGES, Adélia. Design + Artesanato - O caminho brasileiro. São Paulo: Editora Terceiro Nome, 2011.

GOYA, C. R.; ANDRADE, A. B. P.; DOMICIANO, C. L. C.; ROSSI, D. C.; MEDOLA; F. O.; HENRIQUES, F, SILVA, J. P. C., PASCHOARELLI, L. C.; MOURA, M.; RODRIGUES, O. V.; BIGAL, S. M.; BARATA, T. Carnaval, Cultura Popular e Design - Uma Experiência de Extensão Universitária em Design In: Ensaios em Design - Práticas Interdisciplinares.1 ed. Bauru: Canal 6 Editora, 2014, p. 136-156. 
DESIGN POSSÍVEL. Quem Somos. Disponível em:

http://www.designpossivel.org/sitedp/sobre-2/quem-somos/>. Acesso em: 11 de maio de 2016.

SINGER, Paul. Introdução à Economia Solidária. São Paulo: Fundação Perseu Abramo, 2002.

ASSOCIAÇÃO ARTE E CONVÍVIO. Quem Somos. Disponível em:

$<w w w$.arteeconvivio.com.br\%2Fquem_somos.html>. Acesso em 15 de maio de 2016. 